respectively Dutch, Italian, French, and Swedish). The first volume is completed by a dozen papers in groups, dealing with heat transfer, noise (both physical and bio-acoustic), and automatic control.

The second volume opens with a series of substantial papers on boundary layers (particularly boundary-layer control). Next, two general papers survey respectively the subjects of aero-elasticity and of hypersonic flow; they are followed by two papers on ring aerofoils. An interesting Russian contribution from Dorodnicyn deals with the analy tical difficulty of calculation in the transonic region, when the governing equations are changing from elliptic to hyperbolic type. Vertical take-off provides the subject for the next group; materials for heat resistance are then discussed in three papers. Two papers on telemetry, three on aviation medicine matters, and three on propulsion methods for astronautics (including ionic propulsion) conclude the volumes.

The general impression gained from browsing through these volumes is entirely favourable. To weld such a variety of papers from so many different sources into a coherent whole must have presented the editors with a major task; they are to be congratulated on the result. The volumes are admirably printed, and only one or two misprints were noticed. As regards the papers themselves, I do not feel competent to judge more than a few, which I found of high standard; in the many other fields $I$ found much of interest and many papers which invite a second more careful reading.

A. R. Collar

\section{PROGRESS IN METAL PHYSICS}

Progress in Metal Physics

Vol. 7 (1958). Pp. viii +408. 110s. net.

Vol. 8 (1959). Pp. viii +330. 90s. net. Edited by Dr. Bruce Chalmers and Dr. R. King. (London and New York: Pergamon Press.)

7 O say that these two volumes maintain the standard, and the interest, of their predecessors in this series is in itself high praise which is fully deserved. To the authors of the articles-and to the editors it should not be forgotten--are due the thanks of all concerned with the ultimate structures of metals, their transformation by heat or mechanical deformation and their alloys.

Volume 7 contains an account of work on the equilibrium, diffusion and imperfections in semi-conductors, justified, as if this were necessary, by the fact that single crystals of silicon and germanium are now available of a purity and perfection which surpass those of metal crystals "by many orders of magnitude". The paper on the physical metallurgy of titanium alloys is a discussion in terms of the fundamental factors involved, of the question "Wha" additions form useful alloys with titanium ?". It is obvious that the last words in the perennial problems of the thermodynamics and kinetics of martensitic transformations have not yet been said, as is abundantly evidenced by the noteworthy progress made in the past decade, which is excellently sum. marized here. That that part of the mechanical energy expended in deforming a metal and stored up in the deformed structure is the essential feature of the cold-worked state has, in general terms, been recognized for many years. That it is the cause of the instability of this structure is equally well known. The account, therefore, of the extent to which this qualitative treatment may be developed into a quantitative treatment is to be welcomed. The final article, a second one on the properties of metals at low temperatures, deals particularly with thermal conductivity, on which a large amount of work has been done, and on certain mechanical properties.

Volume 8 commences with still a third review in this series of the work-hardening of metals. Despite this, the account of new work extends to some hundred pages with getting on for two hundred references. Allied to this is an article on X-ray studies of deformed metals. The fact that metallic crystals are never perfect has long been known, and an account of the defects in pure metals discusses the subject from the point of view of modern knowledge. "Ten years of fairly intensive work has yielded a moderately complete experimental picture of copper and gold, and the theoretical estimates are apparently reasonably accurate", but "it would be unreasonable to expect to find any easy way of extending our knowledge to other metals".

Two articles remain to be mentioned, one a very welcome discussion on grain boundaries. After a period some thirty to forty years ago when these boundaries were the focus, of metallographic thought, this, under the influence of the then new X-ray techniques, moved over to the structure of the crystals themselves. In view of the profound importance of the grain boundary on the properties, it is a healthy sign that their nature, still very far from being fully understood, should once again be a subject of investigation. Finally there is an account of the sub. structures in crystals grown from the melt, a matter of most obvious significance. The cellular structure on the solid-liquid interface of such a crystal of tin, Fig. 15 , is so full of interest that one is led to wonder whether the old Quincke hypothesis might not repay renewed examination at the hands of a modern physical metallurgist.

An almost incredible amount of work is sum. marized in these volumes, and the need of men wellversed in such matters who can, and are willing to. apply this knowledge to modern industrial needs requires no emphasis.

F. C. Thомpson

\section{FLAME AND EXPLOSION OF GASES AND VAPOURS}

Explosions, Detonations, Flammability and Ignition Part 1: Selected Analytical Studies on Explosions, Detonations, Flammability Limits, and Ignition of Gases, and on Heterogeneous Burning. By Prof. S. S. Penner. Part 2: Experimental and Theoretical Studies of Flammability, Ignitibility and Explosion Prevention. By B. P. Mullins. (AGARDograph No. 31.) Pp. $x i+287$. (London and New York: Pergamon Press, 1959. Published for and on behalf of Advisory Group for Aeronautical Research and Development, North Atlantic Treaty Organization.) 70s. net.

THIS work is largely an account of recent advances in fundamental knowledge of initiation and propagation of flame in engines powered by gaseous and liquid fuels. Other subjects, such as the extinction of flame and the explosion of clouds of certain metallic powders and coal dust, have comparatively brief notices. Solid explosives are not included.

The work has two principal foci, one being the major interests of a professor of jet propulsion and 